\title{
Time-restricted feeding downregulates cholesterol biosynthesis program via RORY- mediated chromatin modification in porcine liver organoids
}

Kexin Zhang ${ }^{1 \dagger}$, Hao $\mathrm{Li}^{1 \dagger}$, Zimeng Xin ${ }^{1 \dagger}$, Yanwei $\mathrm{Li}^{1}$, Xiaolong Wang ${ }^{1}$, Yun Hu${ }^{1}$, Haoyu Liu ${ }^{1 *}$ and Demin Cai ${ }^{1,2^{*}}$ (1)

\begin{abstract}
Background: Time-restricted feeding (TRF) is a dieting strategy based on nutrients availability and diurnal rhythm, shown to improve lipid metabolism efficiency. We have demonstrated previously that retinoic acid-related (RAR) orphan receptor $(\mathrm{ROR}) \mathrm{y}$ is the primary transcription factor controlling cholesterol $(\mathrm{CHO})$ biosynthesis program of animals. However, the functional role of RORY in liver physiology of pigs in response to TRF has not been determined, largely due to the lack of functional models and molecular tools. In the present study, we established porcine liver organoids and subjected them to restricted nutrients supply for 10-h during the light portion of the day.

Results: Our results showed that TRF regimen did not alter hepatocyte physiology, including unchanged cell viability, caspase 3/7 enzyme activity and the gene signature of cell proliferation in porcine liver organoids, compared to the control group $(P>0.05)$. Furthermore, we found that TRF downregulated the hepatic $\mathrm{CHO}$ biosynthesis program at both mRNA and protein levels, along with the reduced cellular $\mathrm{CHO}$ content in porcine liver organoids $(P<0.05)$. Using unbiased bioinformatic analysis of a previous ChIP-seq data and ChIP-qPCR validation, we revealed RORY as the predominant transcription factor that responded to TRF, amongst the 12 targeted nuclear receptors (NRs) $(P<0.05)$. This was likely through RORy direct binding to the MVK gene (encoding mevalonate kinase). Finally, we showed that RORY agonists and overexpression enhanced the enrichment of cofactor p300, histone marks H3K27ac and H3K4me1/2, as well as RNA polymerase II (Pol-II) at the locus of MVK, in TRF-porcine liver organoids, compared to TRF-vector control $(P<0.05)$.
\end{abstract}

Conclusions: Our findings demonstrate that TRF triggers the RORY-mediated chromatin remodeling at the locus of $\mathrm{CHO}$ biosynthesis genes in porcine liver organoids and further improves lipid metabolism.

Keywords: Cholesterol biosynthesis program, Histone modification, Pig, Porcine liver organoids, RORY, Timerestricted feeding

\footnotetext{
* Correspondence: demincai@yzu.edu.cn; Haoyu.Liu0523@outlook.com

${ }^{\dagger}$ Kexin Zhang, Hao Li and Zimeng Xin contributed equally to this work.

${ }^{1}$ College of Animal Science and Technology, Yangzhou University, Yangzhou

225009, PR China

Full list of author information is available at the end of the article
}

(c) The Author(s). 2020 Open Access This article is licensed under a Creative Commons Attribution 4.0 International License, which permits use, sharing, adaptation, distribution and reproduction in any medium or format, as long as you give appropriate credit to the original author(s) and the source, provide a link to the Creative Commons licence, and indicate if changes were made. The images or other third party material in this article are included in the article's Creative Commons licence, unless indicated otherwise in a credit line to the material. If material is not included in the article's Creative Commons licence and your intended use is not permitted by statutory regulation or exceeds the permitted use, you will need to obtain permission directly from the copyright holder. To view a copy of this licence, visit http://creativecommons.org/licenses/by/4.0/ The Creative Commons Public Domain Dedication waiver (http://creativecommons.org/publicdomain/zero/1.0/) applies to the data made available in this article, unless otherwise stated in a credit line to the data. 


\section{Background}

Obesity is a major risk factor for chronic disorders such as nonalcoholic fatty liver disease (NAFLD), cardiovascular disease, and type II diabetes [1]. The etiology of obesity is complex, including nutrient imbalance and the disruption of multiple metabolic pathways in the liver [2, 3]. In addition to the dysregulation of glucose, lipid and cholesterol metabolism, it has been suggested that circadian rhythm is a major contributor to the pathophysiology of obesity [4-6]. The circadian rhythm is an evolutionarily conserved system in mammals that coordinates rhythms of behavior and physiology in response to predictable environmental changes in a near 24-h solar day [7, 8]. Although the circadian clock is a 'build-in' system, it is entrained to the local environment by external cues, including light, temperature and feeding time $[4,5]$.

Time-restricted feeding (TRF), a defined daily period of feeding and fasting $[9,10]$, is increasingly recognized as a preventative intervention against nutritional challenges in animals and humans $[4,6]$. Studies reported that TRF reduces fat depot and weight gain in mice under high-fat feeding and ameliorates metabolic disorders $[11,12]$. It is reported that TRF can also reduce serum cholesterol (CHO) levels in obese mice $[6,11,12]$. Furthermore, TRF downregulates the master lipid regulator peroxisome proliferator-activated receptor $\alpha$ and enzymes involved in triglyceride metabolism in the liver [4], as well as controls hepatic transcriptome in both wild type and the clockdisrupted mice [8]. Remarkably, it has been demonstrated that around $10-15 \%$ of all liver mRNA are expressed in a rhythmic fashion. Many of these genes play a role in cholesterol and glucose metabolism $[4,5,8]$ with one essential part being retinoic acid-related (RAR) orphan receptor (ROR) [4, 13, 14]. Both ROR $\gamma$ and ROR $\alpha$ are involved in controlling hepatic circadian rhythmic expression of glucose genes, whereas mice deficient in RORy showed improved insulin sensitivity and glucose tolerance, especially at daytime [14]. In addition, it is recently reported that $\mathrm{ROR} \gamma$ dictates the entire $\mathrm{CHO}$ biosynthesis pathway in cancerous cells and overrides the classic transcription factor sterol regulatory element-binding protein (SREBP)-2 [13]. However, the role of ROR $\gamma$ in cholesterol biosynthesis in liver physiology of mammals and its relation to TRF remain unclear.

To date, most of the TRF studies were carried out using mice or Drosophila $[5,15,16]$. As light cycle impacts animal circadian phenotype, it is noteworthy that mice are nocturnal, in contrast to diurnal mammals such as humans and pigs [17]. In this regard, pigs (Sus scrofa) are increasingly used as an animal model since they share anatomical, physiological, and immunological similarities with human beings $[18,19]$. Herein we developed a porcine liver organoid model, which combines porcine traits and the ease of genetic manipulation in basic and pharmacological research, as well as to evaluate dieting strategy in livestock management.

Indeed, liver organoid culture is becoming a popular alternative of primary cell culture to recapitulate tissues in a dish $[20,21]$ and to study liver physiology and disease pathogenesis in human and mice [22]. Using extracellular matrix (Matrigel), the unique system enables organoids to resemble architectural and functional properties of in vivo tissue more closely [22], though the establishment using 3D culture could affect cell proliferation, morphogenesis and survival [23]. Nevertheless, such an approach allows the removal of confounding effects and provides a reductionist model of in vivo tissue $[20,22]$, yet not well-established in large animals.

In the current study, the effects of 10 -h TRF on liver tissues were investigated using transcriptomics and chromatin immunoprecipitation, by applying temporal regulation of feeding cells nutrients in porcine liver organoids in vitro. We hypothesized that under normal healthy condition, TRF modifies the cyclical expression of metabolic regulators and associated cellular processes, thus improves metabolism.

\section{Methods}

Animals and the porcine liver organoid establishment All animal procedures were in line with and approved by the Animal Ethical Committee of Yangzhou University (NSFC2020-DKXY-20). Liver tissues were obtained from 3 days old male piglets. Porcine organoids were established and cultured as previously described with modifications [24]. Briefly, dissected liver tissues of newborn piglet were finely minced and transferred to a $50-\mathrm{mL}$ conical tube including a digestion mixture consisting of serum-free DMEM/F-12 medium (Gibco, basal medium) and $2.5 \mathrm{mg} / \mathrm{mL}$ collagenase D (Sigma), and were incubated for $1 \mathrm{~h}$ at $37^{\circ} \mathrm{C}$. Single cells were collected and mixed with $50 \mu \mathrm{L}$ of Matrigel (BD Biosciences) and seeded in 24-well plates (Greiner bio-one) at a density of 1000 per well. When the matrix was solidified, $500 \mu \mathrm{L}$ isolation medium (1:50 B27 supplement without vitamin A), $1: 100 \mathrm{~N} 2$ supplement, $1 \mathrm{mmol} / \mathrm{L} \mathrm{N}$-acetylcysteine, $10 \%$ (vol/vol) Rspo1-conditioned medium, $10 \mathrm{mmol} / \mathrm{L}$ nicotinamide, $10 \mathrm{nmol} / \mathrm{L}$ recombinant human [Leu ${ }_{15}$ ]gastrin I, $50 \mathrm{ng} / \mathrm{mL}$ recombinant human EGF, $100 \mathrm{ng} /$ $\mathrm{mL}$ recombinant human FGF10, $25 \mathrm{ng} / \mathrm{mL}$ recombinant human HGF, $10 \mu \mathrm{mol} / \mathrm{L}$ Forskolin and $5 \mu \mathrm{mol} / \mathrm{L} \mathrm{A83-01,}$ $25 \mathrm{ng} / \mathrm{mL}$ recombinant human Noggin or $5 \%$ ( $\mathrm{vol} / \mathrm{vol}$ ) Noggin-conditioned medium, 30\% (vol/vol) Wnt3aconditioned medium and $10 \mu \mathrm{mol} / \mathrm{L}$ Rho kinase (ROCK) inhibitor were incubated for $4 \mathrm{~d}$. Then the medium was replaced with normal liver expansion medium (1:50 B27 supplement without vitamin A, 1:100 N2 supplement, 1 $\mathrm{mmol} / \mathrm{L} \mathrm{N}$-acetylcysteine, $\quad 10 \% \quad$ (vol/vol) Rspo1- 
conditioned medium, $10 \mathrm{mmol} / \mathrm{L}$ nicotinamide, $10 \mathrm{nmol} /$ $\mathrm{L}$ recombinant human $\left[\mathrm{Leu}^{15}\right.$ ] -gastrin $\mathrm{I}, 50 \mathrm{ng} / \mathrm{mL}$ recombinant human EGF, $100 \mathrm{ng} / \mathrm{mL}$ recombinant human FGF10, $25 \mathrm{ng} / \mathrm{mL}$ recombinant human HGF, $10 \mu \mathrm{mol} / \mathrm{L}$ Forskolin and $5 \mu \mathrm{mol} / \mathrm{L}$ A83-01). The medium was changed every $3-4 \mathrm{~d}$.

\section{Dexamethasone synchronization and sample collection}

At day 15 from seeding, organoids of 12 wells were treated with $100 \mathrm{nmol} / \mathrm{L}$ (final concentration) of dexamethasone (DEX, Sigma-Aldrich) for $15 \mathrm{~min}$ to synchronize. The organoids were then washed three times with $\mathrm{PBS}\left(37^{\circ} \mathrm{C}\right)$ and were incubated in expansion medium. Forty-eight hours after DEX treatment, organoids of 6 wells as control group were exposed to expansion medium for $14 \mathrm{~h}$ from 8:00 to 22:00 and to basal medium for $10 \mathrm{~h}$ from 22:00 to 8:00 (+1 d) in a 24-h cycle. Whereas organoids of the other 6 wells as TRF group were exposed to expansion medium for $10 \mathrm{~h}$ from 8:00 to 18:00 and to basal medium for $14 \mathrm{~h}$ from 18:00 to 8:00 $(+1 \mathrm{~d})$ in a $24-\mathrm{h}$ cycle (Fig. 1). The exposure in the pattern of 24-h cycle was continued to $7 \mathrm{~d}$ and the organoids were harvested directly at 8:00 for fundamental testing. For the compounds/lentivirus treatment, the organoids were treated at 8:00 from the end of the $7^{\text {th }}$ day of 24-h cycle for another 48 -h period and then harvested for measurements.

\section{Cell viability and caspase $3 / 7$ activity in organoids}

The organoids were seeded in 96-well plates at the density of 100 organoids in $10 \mu \mathrm{L}$ Matrigel per well in a total volume of $100 \mu \mathrm{L}$ expansion medium for $7 \mathrm{~d}$ exposure of the above $14 / 10 \mathrm{~h}$ feeding window and incubated with expansion medium for $48 \mathrm{~h}$. Carefully aspirating the medium and adding $100 \mu \mathrm{L}$ live/dead reagents (Thermofisher Scientific) for $30 \mathrm{~min}$ incubation at room temperature. Fluorescence microscopy was used to capture signals of a cell-permeant dye Calcein AM that represents live cells, and signals of ethidium bromide homodimer-1 to identify dead cells. Besides, Cell-Titer GLO reagents (Promega) were added and luminescence was measured on GLOMAX microplate luminometer (Promega) according to the manufacturer's instructions. The caspase-3/7 activity was determined using a luminescent caspase-Glo 3/7 assay kit (Promega Corporation, Madison, USA) following the manufacturer's instructions. The above assays were performed in triplicates and the entire experiments were repeated three times.

\section{qRT-PCR and western blotting analysis}

Total RNA of $2 \mu \mathrm{g}$ was isolated from organoids in 24well plates, and the cDNA was prepared, amplified and measured using SYBR green as previously described [13]. Briefly, the fluorescent values were collected, and a melting curve analysis was performed. Fold difference was calculated [13]. The primers are shown in Table S1. The experiments were performed at least three times with data presented as mean values \pm SD. Organoids lysates were analyzed by western blotting with antibodies specifically recognizing the indicated proteins shown in Table S2.

\section{Ectopic lentivirus production}

For ROR $\gamma$ overexpression, porcine $\mathrm{ROR} \gamma$ cDNA in pLX304 (DNASU) was amplified and cloned into a modified pLX304 vector as previously described [13]. Lentiviral particles were produced in $293 \mathrm{~T}$ cells after co-transfection of the above lentivirus vectors, psPAX2 and PMD2.G in $10-\mathrm{cm}$ dishes.

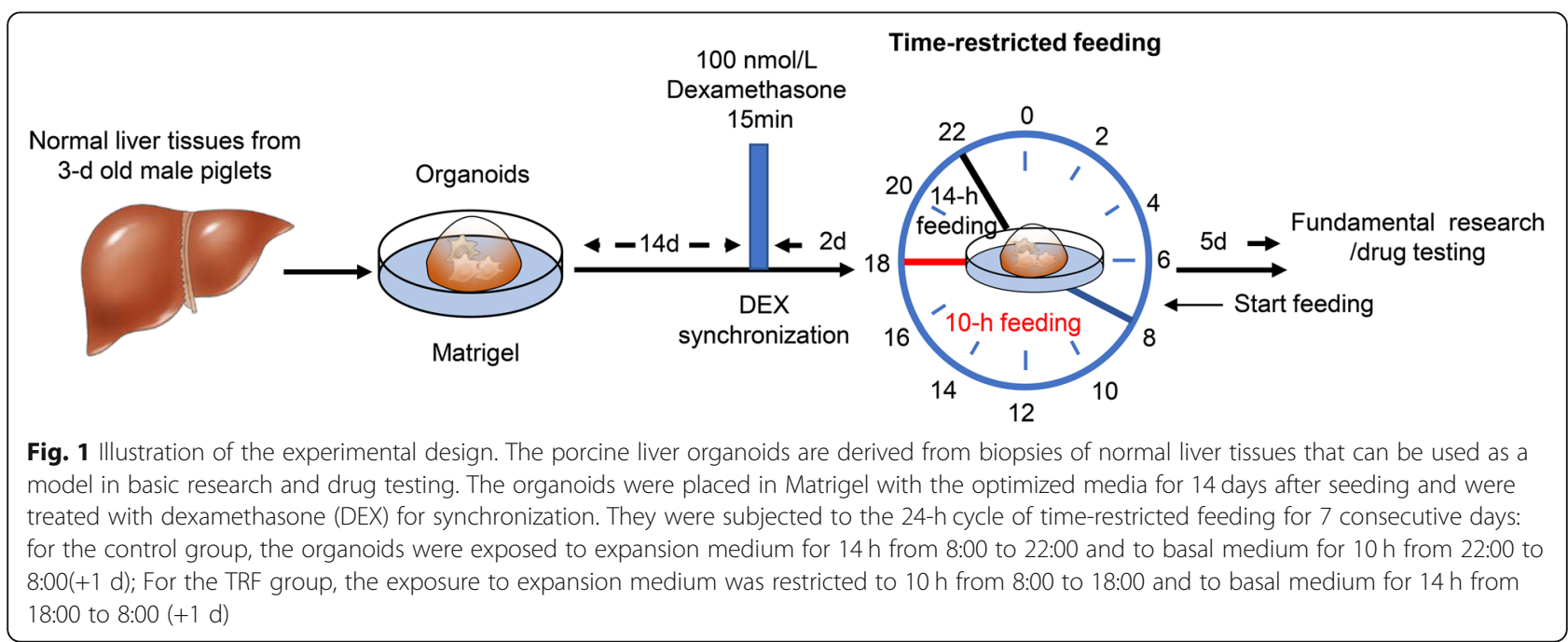




\section{Measurement of cholesterol contents}

Organoids were washed three times with cold PBS and subjected to extraction with organic solvents (7:11:0.1, chloroform/isopropanol/Triton X-100). Free (3-OH) and total (3-OH and esters) sterol levels were measured using Amplex ${ }^{\text {tw }}$ Red Cholesterol Assay Kit (Thermofisher Scientific) and normalized to protein concentrations. All experimental points were set up as sextuplicate as biological replication and the entire experiments were repeated three times.

\section{ChIP-qPCR analysis and ChIP-seq data analysis}

Briefly, organoids of 24-well plates were pelleted in cold PBS and resuspended in fixing buffer $(50 \mathrm{mmol} / \mathrm{L}$ Hepes-KOH, $100 \mathrm{mmol} / \mathrm{L} \mathrm{NaCl}, 1 \mathrm{mmol} / \mathrm{L}$ EDTA, 0.5 $\mathrm{mol} / \mathrm{L}$ EGTA) before subject to crosslinking in $1 \%$ formaldehyde for 5 min followed by quenching with glycine for $5 \mathrm{~min}$ on ice. The pellets were collected by centrifugation and resuspended in lysis buffer $(50 \mathrm{mmol} / \mathrm{L} \mathrm{HEPE}$ $\mathrm{S} \mathrm{pH} 8.0,140 \mathrm{mmol} / \mathrm{L} \mathrm{NaCl}, 1 \mathrm{mmol} / \mathrm{L}$ EDTA, $10 \%$ glycerol, $0.5 \%$ NP40, $0.25 \%$. Triton X100). The pellets were then resuspended in washing buffer $(10 \mathrm{mmol} / \mathrm{L}$ Tris $\mathrm{pH} 8.0,1 \mathrm{mmol} / \mathrm{L}$ EDTA, $0.5 \mathrm{mmol} / \mathrm{L}$ EGTA, $200 \mathrm{mmol} /$ $\mathrm{L} \mathrm{NaCl}$ ), washed and resuspended in shearing buffer (0.1\% SDS, $1 \mathrm{mmol} / \mathrm{L}$ EDTA, pH 8, $10 \mathrm{mmol} / \mathrm{L}$ Tris $\mathrm{HCl}$, $\mathrm{pH} 8$ ) before sonication using Covaris E220 following manufacturer's instructions. Chromatin fragments were precipitated using specific antibodies and protein G beads, washed, and treated with proteinase $\mathrm{K}$ and RNase A. Purified ChIP DNA was then used for ChIP-qPCR analysis. The forward and reverse primers for ChIPqPCR are "GCTCCATCCGGGAGACACACAA" and "GCAGGGTCAATGTGCAGTTTCT" respectively.

ChIP-qPCR analysis was performed as described previously [13]. The antibodies used for the RNAPII (Santa Cruz, sc-899); H3K4me1(Abcam, ab8895); H3K4me2 (Abcam, ab32356); H3K4me3 (Abcam, ab8580); H3K27ac (Abcam, ab4729); p300 (Abcam, ab10485); anti-ROR $\gamma$ rabbit serum was generated by Covance, using purified GST-human ROR $\gamma$ fragment (amino acids 79-301) expressed in Escherichia coli, SRC-1 (Santa Cruz, sc-8995); SRC-3/ACTR65 and IgG (Santa Cruz, sc-2027). ChIPs were performed with each experimental point in triplicate, and each experiment was repeated three times.

Fastq files from previous datasets [13] were processed by the pipeline of AQUAS Transcription Factor and Histone (https://github.com/kundajelab/chipseq_pipeline). Briefly, sequencing tags were mapped against the reference genome using BWA 0.7.15 [25]. Uniquely mapped tags filtering and deduping were used for peak calling by model-based analysis for ChIP-seq (MACS; 2.1.0) to identify regions of ChIP-seq enrichment over background. Normalized genome-wide signal-coverage tracks from raw-read alignment files were built by MACS2, UCSC tools (bedGraphToBigWig/bedClip; http:// hgdownload.cse.ucsc.edu/admin/exe/linux.x86_64/) and bedTools (https://github.com/arq5x/bedtools2). Visualization of ChIP-seq signal at enriched genomic regions (avgprofile and heatmap) was achieved by using deepTools (https://deeptools.readthedocs.io/en/develop/ index.html).

\section{Bioinformatic analyses using clinical dataset}

METABRIC data sets were downloaded from cBioPortal website at http://www.cbioportal.org/study?id=brca metabric\#summary. The data were then $\log _{2}$ transformed and quantile normalized before further analysis. Principal component analysis (PCA) was carried out with R 'COMPADRE' package [26]. After PCA transformation, the samples were visualized according to pathway activity score using 'gplots' $\mathrm{R}$ packages. Based on the pathway activity score and the gene profile across the samples, the Pearson correlation metric was computed between each gene by using the 'cor' function in R.

\section{Statistics}

Statistical analyses were performed by GraphPad Prism software 7.0. The data are presented as mean values \pm SD from at least three independent experiments. Statistical analysis was performed using two-tailed Student's $t$ tests or ANOVA with Tukey's post hoc test to compare the means. $P<0.05$ was considered significant.

\section{Results}

Time-restricted feeding does not affect cell growth and survival in porcine liver organoids

Given that organoids are more physiologically relevant than 2D monolayers cells, we developed the porcine liver organoids. Firstly, we evaluated the effects of TRF using live/dead regents (calcein AM/ethidium bromide homodimer-1). Immunofluorescent staining showed that TRF did not affect the hepatocytes viability (Fig. 2a), which was further confirmed by quantification of adenosine triphosphate (ATP) presence in cells using a celltiter measurement, indicative of metabolically active cells (Fig. 2b, $P>0.05$ ). In addition, there was no difference of the caspase $3 / 7$ enzyme activity between the control and TRF treated organoids (Fig. 2c, $P>0.05$ ). In line with this, TRF had no effects on the key proliferation and survival genes expression in the porcine liver organoids, compared to that in control (Fig. $2 \mathrm{~d}, P>0.05$ ). These data demonstrated that the 10-h TRF regimen does alter hepatocytes physiology significantly in our established porcine liver organoids. 


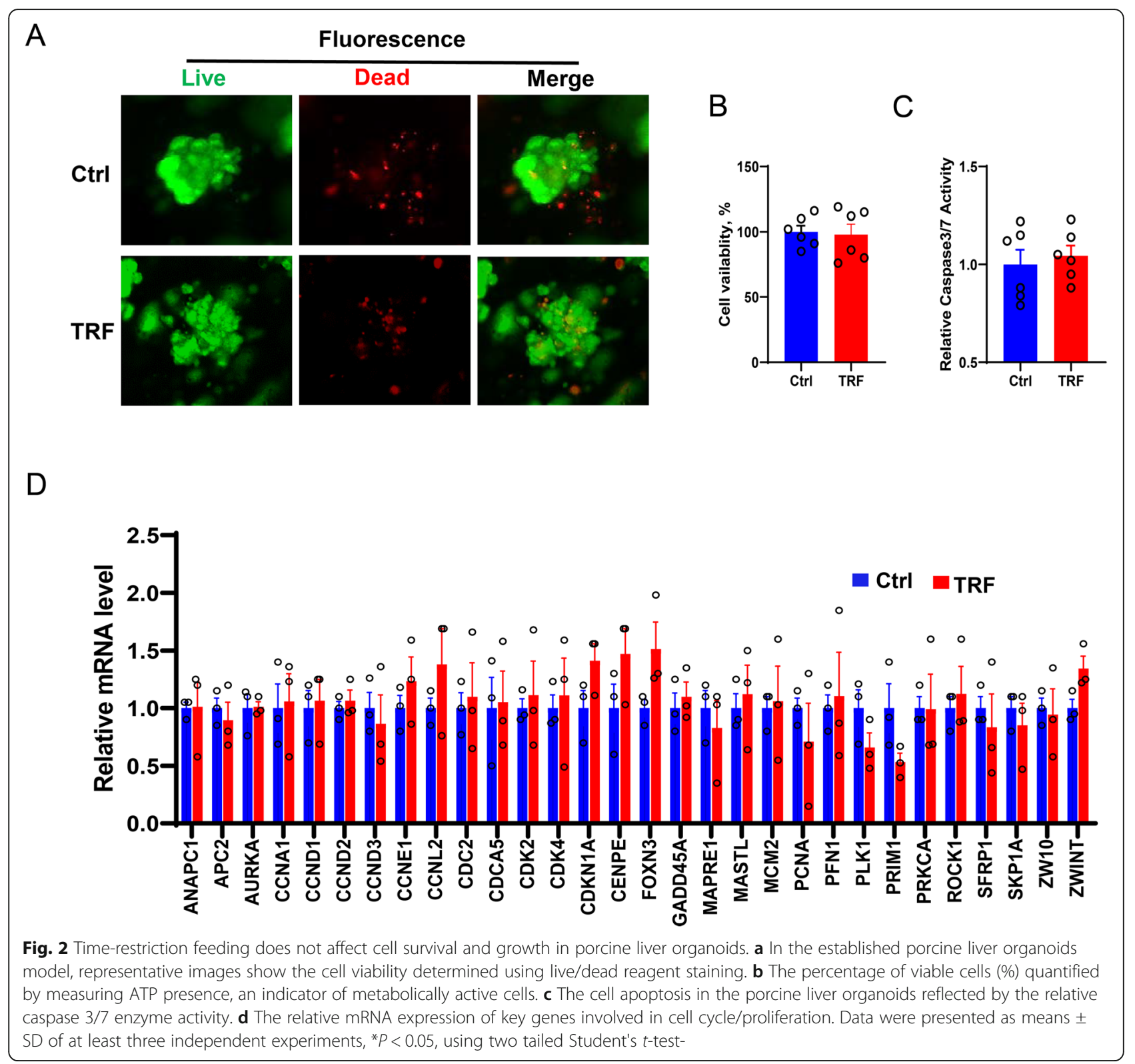

Time-restricted feeding downregulates cholesterol biosynthesis program

Previous studies have demonstrated that TRF resulted in lower $\mathrm{CHO}$ levels in circulation of mice $[8,27]$. We thus examined both total and free $\mathrm{CHO}$ levels, and showed significantly decreased $\mathrm{CHO}$ content in organoids under TRF, compared to the control group (Fig. $3 \mathrm{a}, \mathrm{b}, P<0.05$ ). Furthermore, the expression of key genes involved in $\mathrm{CHO}$ biosynthesis were investigated. Consistently, genes such as $M V K$ (encoding mevalonate kinase), FDPS (encoding farnesyl pyrophosphate synthase), FDFT1 (encoding farnesyl-diphosphate farnesyltransferase 1), SQLE (encoding Squalene monooxygenase), EBP (encoding emopamil binding protein), SC5D (encoding sterol-c5desaturase), DHCR7 (encoding 7-Dehydrocholesterol reductase) and DHCR24 were significantly downregulated in TRF group (Fig. 3c). In line with the mRNA levels, TRF resulted in strong downregulation of the $\mathrm{CHO}$ biosynthesis enzyme proteins including MVK, FDFT1, SQLE, EBP and DHCR24 (Fig. 3d). These results indicated that the $\mathrm{CHO}$ biosynthesis program is responsive to TRF treatment.

\section{RORY is linked to TRF-induced $\mathrm{CHO}$ downregulation}

Cholesterol biosynthesis pathway is under the tight regulation of major transcription NRs, such as liver X receptors and RORs $[13,28]$. To identify potential drivers of the decreased $\mathrm{CHO}$ biosynthesis program in TRF treated organoids, we tested a panel of 20 small-molecule modulators targeting members of the NR family in liver 
A

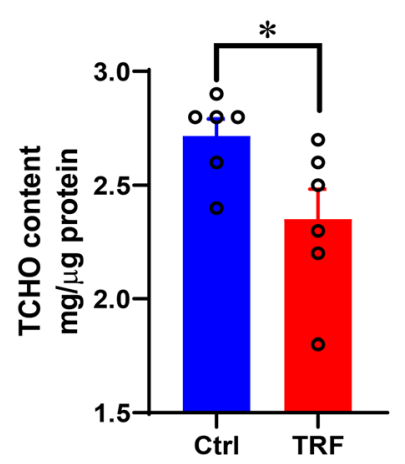

C
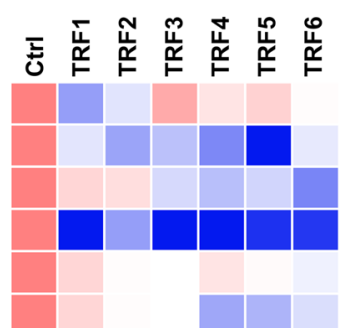

IDI 1

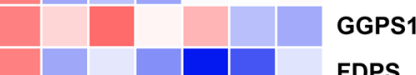

\begin{tabular}{l|l|l|l|l|l|l|l}
\hline & & & & & FDPS \\
\hline & & & & & FDFT1
\end{tabular}

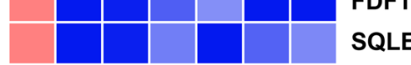

LSS

CYP51A1

TM7SF2

MSMO1

NSDHL

HSD17B7

EBP

SC5D

DHCR7

DHCR24
B

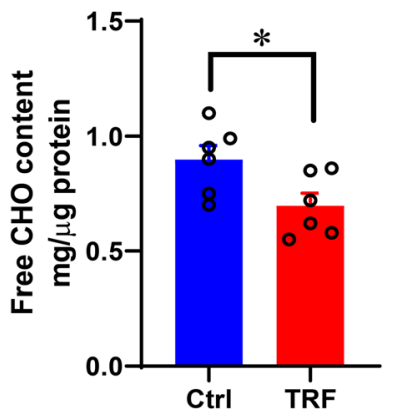

D

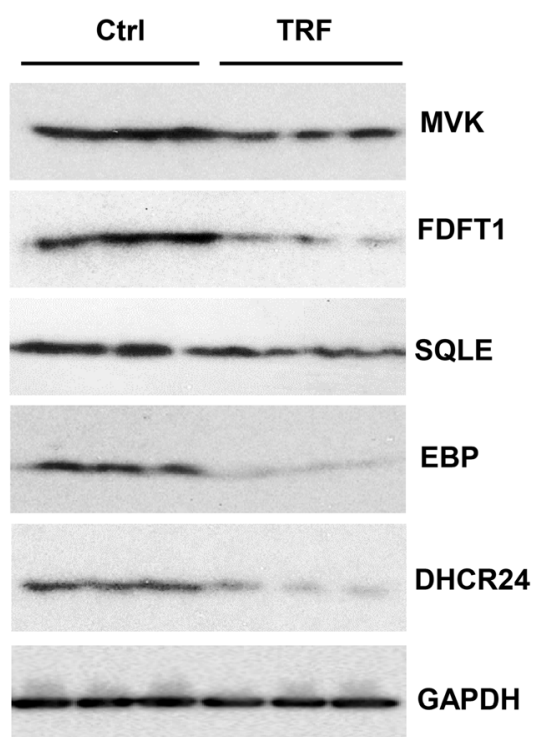

Fig. 3 TRF reduces cholesterol biosynthesis program in porcine liver organoids. $\mathbf{a}, \mathbf{b}$ Total and free $\mathrm{CHO}$ contents in organoids (mg/ $\mathrm{mg}$ protein). c Key genes expression ( $\left.\log _{2}\right)$ of $\mathrm{CHO}$ biosynthesis normalized to control. d Western blotting analysis of CHO biosynthesis enzymes MVK, FDFT1, SQLE, EBP, DHCR24 selected based on mRNA expression (c), whereas GAPDH was used as an internal reference. Data were presented as means \pm SD of at least three independent experiments, ${ }^{*} P<0.05$, using two tailed Student's $t$-test

organoids (Fig. 4a). Intriguingly, the $\mathrm{ROR} \gamma$ agonists SR0987 and desmosterol showed strongest capacity to rescue cellular $\mathrm{CHO}$ contents reduction induced by TRF (Fig. 4a, $P<0.05)$. Consistently, we found that the significantly downregulated expression of genes involved in $\mathrm{CHO}$ biosynthesis were restored to the levels that comparable to control (Fig. 4b). Furthermore, we analyzed the relevant clinical dataset and revealed a strong positive relationship between the expressions of ROR $\gamma$ gene RORC and MVK $(r=0.2383, P<0.0001)$, FDPS $(r=$ $0.1228, P=0.0338), E B P(r=0.2233, P<0.0001)$ and
DHCR24 ( $r=0.4039, P<0.0001)$, respectively. Together, these data suggested that ROR $\gamma$ is a key factor linked to the decreased $\mathrm{CHO}$ biosynthesis program in TRF treated organoids.

\section{$\mathrm{ROR} y$ is required for TRF-induced $\mathrm{CHO}$ biosynthesis program downregulation}

Next, we investigated whether TRF downregulates $\mathrm{CHO}$ biosynthesis program via RORY signaling. First, we examined the endogenous expression of $\mathrm{ROR} \gamma$ in porcine liver organoids with qRT-PCR and western blotting, and 


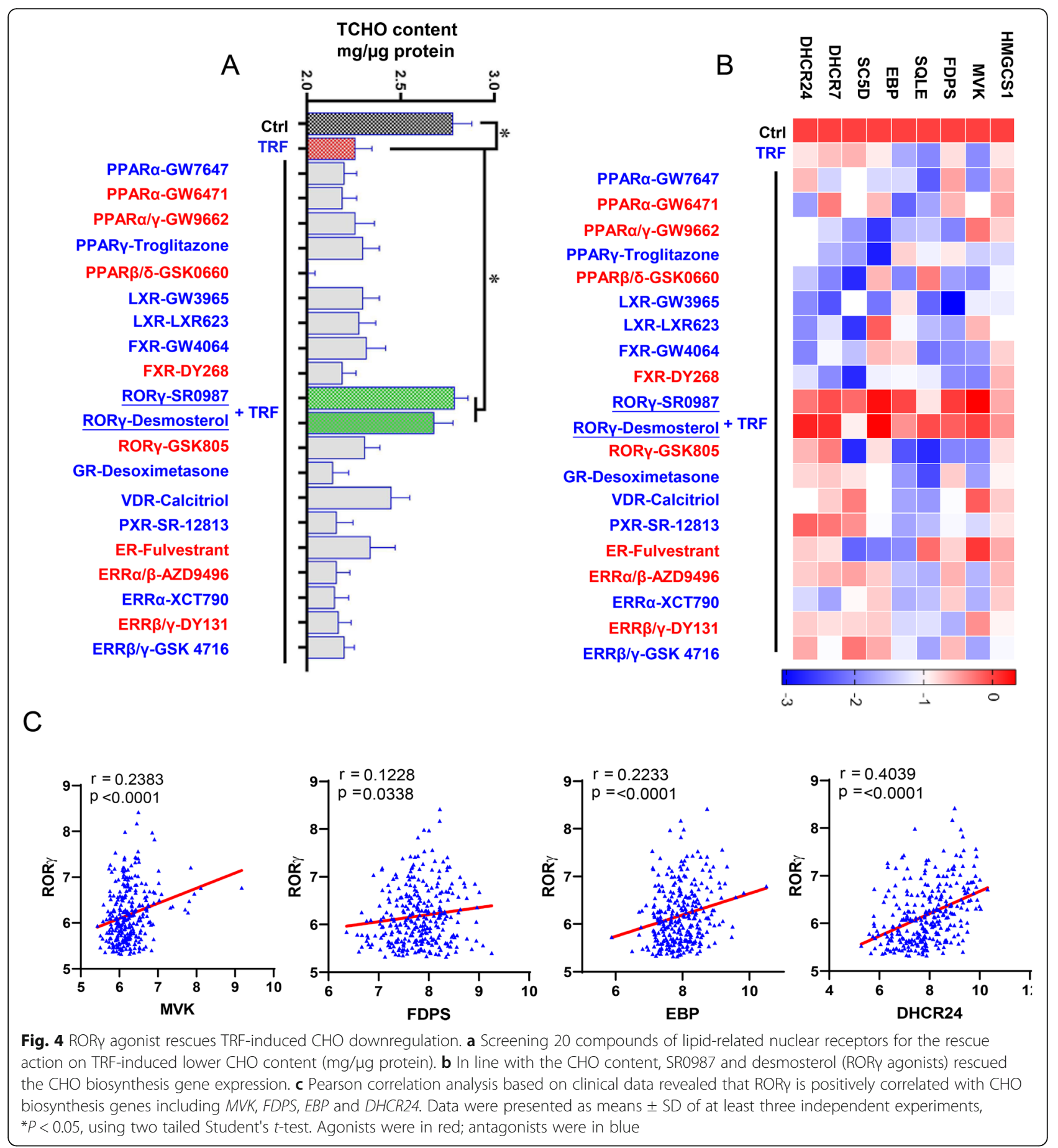

found that both mRNA $(P<0.001)$ and protein abundances were significantly decreased in TRF treated organoids, when comparing to the controls (Fig. 5a, b). To determine whether elevated ROR $\gamma$ alone is sufficient to promote the $\mathrm{CHO}$ biosynthesis program, we overexpressed ROR $\gamma$ in TRF treated organoids and confirmed its high expression compared to vector controls (Fig. 5c, $P<0.001$ ). Secondly, as shown in Fig. 5d, ectopic ROR $\gamma$ significantly enhanced the
CHO content of TRF treated organoids, but not of the Vector-Ctrl group $(P<0.05)$. Similarly, the key $\mathrm{CHO}$ biosynthesis genes were significantly upregulated by overexpressed ROR $\gamma$, compared to the Vector-TRF group (Fig. 5e, $P<0.05$ ). There was a trend that $\mathrm{ROR} \gamma$ overexpression in the organoids caused higher expression of these $\mathrm{CHO}$ biosynthesis genes than the Vector-Ctrl group, although no statistical significance reached. Together, these results 


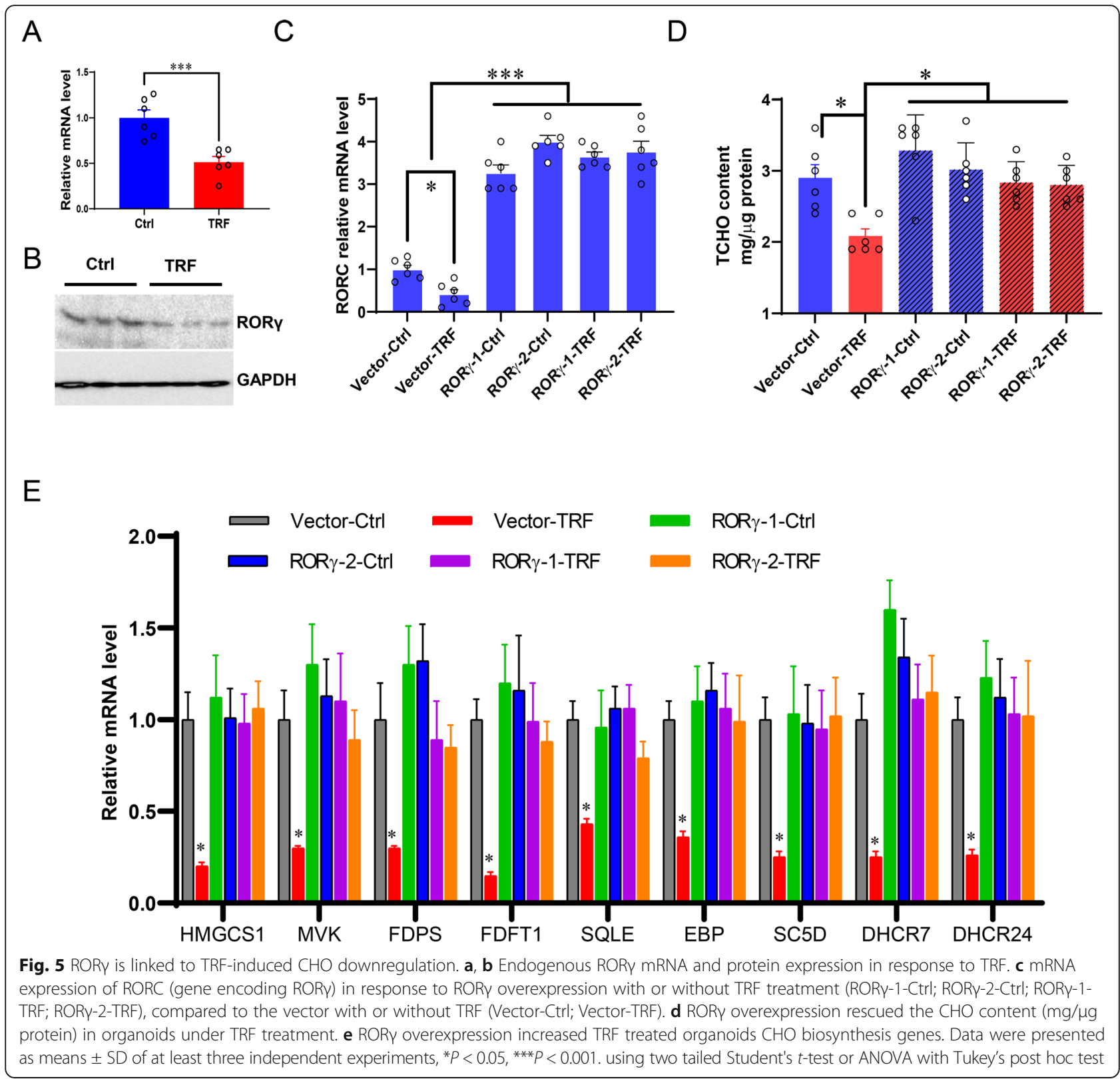

suggested that ROR $\gamma$ plays a direct role in the TRF regulation of $\mathrm{CHO}$ biosynthesis program.

\section{Time-restriction feeding reduces RORY enrichment on MVK gene promoter}

To dissect molecular components of the ROR $\gamma$ pathway in the TRF downregulating $\mathrm{CHO}$ biosynthesis program, we examined the impact of TRF on RORY recruitment to chromatin targets. Firstly, we performed the analysis of an available ChIP-seq data [13, 14, 29], and the results showed that ROR $\gamma$ peaks are present on $M V K$ gene both in human (top) and mouse (bottom) (Fig. 6a). It is wellknown that the specific sequence motifs of $\mathrm{ROR} \gamma$ binding DNA including $\mathrm{A}(\mathrm{A} / \mathrm{T}) \mathrm{NTAGGTCA}$ (the classic ROR element motif) or C(T/A)(G/A)GGNCA (the variant RORE motif) [30]. In consistent with the $M V K$ ROR $\gamma$ peak location in human or mouse, ChIP-qPCR of regions containing 12 putative ROREs across the MVK locus demonstrated that RORy bound to a site around the transcription start site (TSS) region in porcine liver organoids (Fig. 6b). As shown in Fig. 6c, the site contains sequences that match the motif AGGTCA. When organoids were exposed to TRF, RORy binding was reduced compared to control (Fig. 6d, $P<0.01$ ). We next assessed the efficiency of ROR $\gamma$ agonist to restore ROR $\gamma$ binding, SR0987 or desmosterol treatment enhanced 2- 


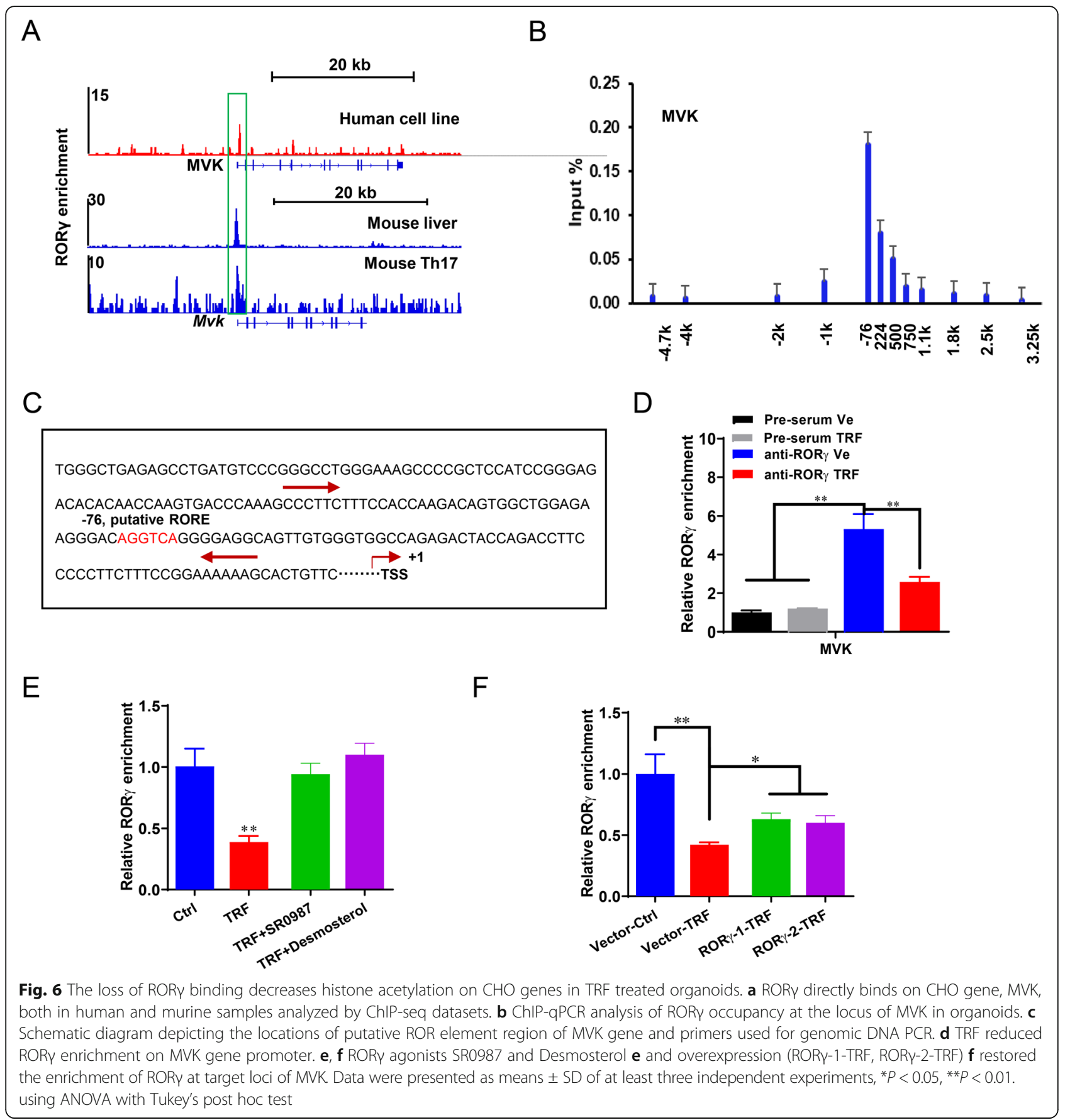

fold RORy occupancy on MVK gene promoter in the TRF treated organoids (Fig. 6e, $P<0.01$ ). Interestingly, $\mathrm{ROR} \gamma$ enrichment was only increased $50 \%$ by $\mathrm{ROR} \gamma$ overexpression in TRF treated organoids, compared to the vector-TRF group (Fig. $6 f, P<0.05$ ). These data indicated that other factors may also contribute to the ROR $\gamma$-mediated chromatin modifications in the TRF controlled $\mathrm{CHO}$ biosynthesis programming, than $\mathrm{ROR} \gamma$ endogenous expression.
Time-restriction feeding modifies transcription-complex modifications on the loci of RORY binding

Next, we investigated whether transcription co-factors or histone modifications facilitated the actions of ROR $\gamma$ in the regulation of $\mathrm{CHO}$ biosynthesis program in TRF treated organoids. The putative co-factors p300, SRC-1 and SRC-3 were predicted by STRING analysis from ELIXIR database (Fig. 7a). Of the three factors, only p300 occupancy was significantly reduced on the $M V K$ 


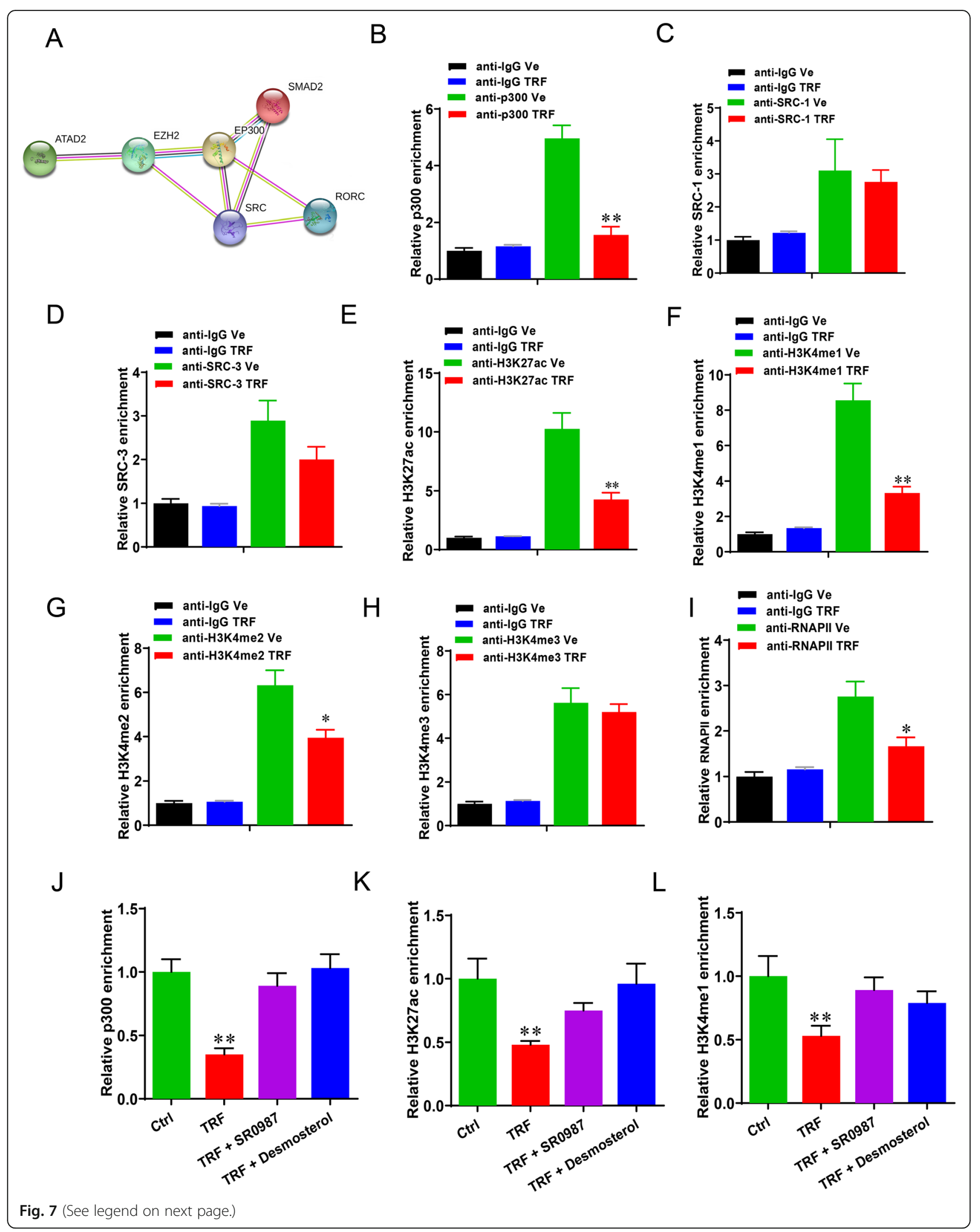


(See figure on previous page.)

Fig. 7 Time-restricted feeding modifies histones modification on the loci of RORY binding. a Putative co-factors of RORy transcriptional regulation were predicted by STRING. b-d The relative enrichment of RORy co-factors (p300, SRC-1 and SRC-3) at the locus of MVK in organoids analyzed by ChIP-qPCR. e-i The relative enrichment of histone marks (H3K27ac, H3K4me1/2/3) and RNA polymerase II occupancy analyzed by ChIP-qPCR. $\mathbf{j}-\mathbf{I}$ RORy agonists SR0987 and Desmosterol enhanced the occupancies of p300, H3K27ac and H3K4me1 at target loci MVK of TRF treated organoids. Data were presented as means \pm SD of at least three independent experiments, ${ }^{*} P<0.05,{ }^{* *} P<0.01$. using ANOVA with Tukey's post hoc test

gene in the TRF treated organoids, compared to that of control (Fig. 7b-d, $P<0.01$ ). We then performed ChIPqPCR to detect the transcriptional activation-linked histone marks H3K27ac, H3K4me1/2/3 at the locus of MVK. The results showed that TRF significantly decreased the enrichment of H3K27ac (Fig. 7e, $P<0.01$ ), H3K4me1/2 (Fig. 7f, g, $P<0.01$ ), but not H3K4me3 (Fig. $7 \mathrm{~h}, P>0.05$ ). In line with the reduction of mRNA levels of $\mathrm{CHO}$ biosynthesis genes, promoter occupancies of RNA polymerase II (Pol-II) was also reduced at the target loci in the TRF treated organoids (Fig. $7 \mathrm{i}, P<0.05$ ). Furthermore, ROR $\gamma$ agonists enhanced the enrichments of p300, H3K27ac and H3K4me1 in the organoids exposed to TRF (Fig. 7j-l, $P<0.01)$. Taken together, these results implied that TRF triggers the ROR $\gamma$-associated chromatin remodeling at the locus of $\mathrm{CHO}$ biosynthesis genes.

\section{Discussion}

Temporal regulation of feeding, i.e. TRF in animal husbandry, may offer a dieting strategy to modify metabolism through the oscillation of hepatic genes expression that are key metabolic regulators $[4,8]$. In the current study, we used porcine liver organoids and showed that 10-h TRF regimen does not alter cell viability, proliferation, or apoptosis. Instead, TRF down-regulated hepatic cholesterol biosynthesis program involving MVK, FDFT1, SQLE, EBP and DHCR24 expressions at both mRNA and protein level, associated with the reduced $\mathrm{CHO}$ output in the TRF treated organoids. Subsequently, our search for responsible transcription factors focusing on NRs uncovered the predominant role of ROR $\gamma$. In that ROR $\gamma$ agonist SR0987 and ROR $\gamma$ overexpression reprogrammed the $\mathrm{CHO}$ biosynthesis pathway induced by TRF in porcine liver organoids. Finally, we demonstrated that ROR $\gamma$ directly binds to MVK gene, whereas TRF downregulates $\mathrm{CHO}$ pathway via RORYmediated chromatin remodeling.

Interactions between circadian clock and metabolism can be affected by nutrition quality, quantity or daily eating pattern. Given the growing use of pigs in basic research, as well as in agriculture [18, 31], it is necessary to understand the extent to which circadian rhythms affect this species. By employing a 10-h TRF regimen, we observed a downregulation of $\mathrm{CHO}$ biosynthesis program, thus a TRF resultant decreased $\mathrm{CHO}$ output in the porcine liver organoids. In accordance, a substantial amount of studies demonstrate that various TRF strategies protect individuals from diet induced obesity and metabolic disorders $[6,10,32]$. For instance, Hatori et al. have shown that 8 -h TRF reduced hepatic steatosis and hyperinsulinemia through cAMP-response element binding protein, mTOR (mammalian target of rapamycin) and AMP-activated protein kinase pathways in mice [11]. Recently, 10-h time-restriction eating has been applied to patients diagnosed with metabolic syndrome and showed positive effects including improved body weight, blood pressure and lowered cholesterol levels [10].

Although it is suggested that counteracting hypercholesterolemia is a general hallmark of TRF [6,33], liver is the master regulator of cholesterol homeostasis of mammals. Our analysis based on clinical data revealed that hepatic expression of MVK, FDPS, EBP and DHCR24 are all positively correlated with the expression of NR family of transcription factor, ROR $\gamma$. These genes, e.g., MVK encodes mevalonate kinase enzyme, catalyzing the conversion of $\mathrm{CHO}$ precursor [34], along with several others that were shown to participate in the TRFreduced $\mathrm{CHO}$ biosynthesis program in our study. The link of $\mathrm{CHO}$ genes to RORy is of great interest, as ROR $\gamma$ is involved in the direct regulation of circadian rhythm by binding to the main clock gene [35]. Studies have revealed that approximately $10 \%$ of all liver mRNA are expressed in a rhythmic fashion $[8,36]$. We hypothesized that $\mathrm{ROR} \gamma$ may represent the dominant respondent of liver oscillator in our TRF-treated porcine liver organoids. Indeed, we found that TRF decreased ROR $\gamma$ expression at both mRNA and protein level in porcine liver. While ROR $\gamma$ agonist rescued the TRF-resulted $\mathrm{CHO}$ downregulation, amongst 20 compounds targeting NRs. To support this, it is demonstrated in another study that hepatocyte-specific ROR $\gamma$ knockout mice exhibit improved insulin sensitive due to reduced gluconeogenesis, but also changed lipid metabolic genes [14]. Inversely, we showed that hepatocytes ectopic ROR $\gamma$ disrupted TRF induced-CHO biosynthesis genes downregulation and increased $\mathrm{CHO}$ end product in porcine liver organoids, pointing to the critical role of ROR $\gamma$ as the master transcription factor.

It has long been considered that SREBP-2 is the primary transcription factor for activation of genes involved in $\mathrm{CHO}$ biosynthesis [37-39], including MVK [40]. In contrast, our previous study has demonstrated that 
ROR $\gamma$ plays a dominant function over that of SREBP-2 in controlling $\mathrm{CHO}$ biosynthesis program in cancerous cells [13], which is in line with our current demonstration. By further examining the downstream events, we identified a ROR $\gamma$ binding site in the DNA sequence of MVK in porcine liver organoids. We have shown clearly that TRF reduces ROR $\gamma$ enrichment at the locus of $\mathrm{MVK}$, involving the reduced enrichments of co-factor p300 and histone marks H3K27ac and H3K4me1/2. While ROR $\gamma$ agonists enhanced the occupancies of p300, H3K27ac and H3K4me1 at target loci against TRF regulation. We therefore suggested that RORY is a targetable master regulator of $\mathrm{CHO}$ biosynthesis program during the temporal regulation of feeding and beyond.

\section{Conclusions}

In conclusion, we identified a novel connection between the regulator ROR $y$ and the temporal regulation of hepatic $\mathrm{CHO}$ biosynthesis program in porcine organoids. Our findings showed the potential of organoids to be used as a platform for mechanistic studies and drug testing. More importantly, we contributed to the development of an optimal long-term organ culture and its application to animal husbandry. Challenges remain as to capture complex pathologies of liver diseases in a dish, such as inflammation and fibrosis [41], and further studies are warranted.

\section{Supplementary information}

Supplementary information accompanies this paper at https://doi.org/10. 1186/s40104-020-00511-9.

Additional file 1: Table S1. Nucleotide sequences of specific primers used for real-time PCR.

Additional file 2: Table S2. Antibodies used.

\section{Abbreviations}

ATP: Adenosine triphosphate; CHO: Cholesterol; DEX: Dexamethasone; DHCR7: 7-Dehydrocholesterol reductase; EBP: Emopamil binding protein; FDFT1: Farnesyl-diphosphate farnesyltransferase 1; FDPS: Farnesyl pyrophosphate synthase; mTOR: Mammalian target of rapamycin; MVK: Mevalonate kinase; NAFLD: Nonalcoholic fatty liver disease; NRs: Nuclear receptors; PCA: Principal component analysis; Pol-II: Polymerase II; ROCK: Rho kinase; ROR: Retinoic acid-related (RAR)-related orphan receptor; RORE: ROR element; SC5D: Sterol-C5-desaturase; SQLE: Squalene monooxygenase; SREBP-2: Sterol regulatory element-binding protein-2; TRF: Time-restricted feeding; TSS: Transcription start site

\section{Acknowledgements}

Not applicable.

\section{Authors' contributions}

D.C. conceived the study. K.Z., H.L., Z.X., Y.L., X.W. and Y.H. performed the experiments. D.C. and H.Y.L. wrote the manuscript. D.C. supervised the study and approved the final version. All authors read and approved the final manuscript.

\section{Funding}

This work was supported by the Postgraduate Research \& Practice Innovation Program of Yangzhou University (X20200616) and the Priority
Academic Program Development of Jiangsu Higher Education Institutions (PAPD).

Availability of data and materials

The datasets analyzed during the current study are available from the corresponding author upon request.

Ethics approval and consent to participate

Not applicable.

Consent for publication

Not applicable.

\section{Competing interests}

The authors declare that they have no competing interests.

\section{Author details}

${ }^{1}$ College of Animal Science and Technology, Yangzhou University, Yangzhou 225009, PR China. ${ }^{2}$ Institute of Epigenetics and Epigenomics, Yangzhou University, Yangzhou 225009, PR China.

Received: 20 April 2020 Accepted: 8 September 2020

Published online: 02 November 2020

\section{References}

1. Engin A. The definition and prevalence of obesity and metabolic syndrome Adv Exp Med Biol. 2017;960:1-17.

2. Swinburn BA, Sacks G, Hall KD, McPherson K, Finegood DT, Moodie ML, et al. The global obesity pandemic: shaped by global drivers and local environments. Lancet. 2011;378(9793):804-14.

3. Jung UJ, Choi M-S. Obesity and its metabolic complications: the role of adipokines and the relationship between obesity, inflammation, insulin resistance, dyslipidemia and nonalcoholic fatty liver disease. Int J Mol Sci. 2014;15(4):6184-223

4. Adamovich Y, Rousso-Noori L, Zwighaft Z, Neufeld-Cohen A, Golik M, KrautCohen J, et al. Circadian clocks and feeding time regulate the oscillations and levels of hepatic triglycerides. Cell Metab. 2014:19(2):319-30.

5. Panda S. Circadian physiology of metabolism. Science. 2016;354(6315):1008-15.

6. Chaix A, Lin T, Le HD, Chang MW, Panda S. Time-restricted feeding prevents obesity and metabolic syndrome in mice lacking a circadian clock. Cell Metab. 2019;29(2):303-19 e304.

7. Barber AF, Erion R, Holmes TC, Sehgal A. Circadian and feeding cues integrate to drive rhythms of physiology in Drosophila insulin-producing cells. Genes Dev. 2016:30(23):2596-606.

8. Vollmers C, Gill S, DiTacchio L, Pulivarthy SR, Le HD, Panda S. Time of feeding and the intrinsic circadian clock drive rhythms in hepatic gene expression. Proc Natl Acad Sci U S A. 2009;106(50):21453-8.

9. Varady KA, Bhutani S, Church EC, Klempel MC. Short-term modified alternate-day fasting: a novel dietary strategy for weight loss and cardioprotection in obese adults. Am J Clin Nutr. 2009:90(5):1138-43.

10. Wilkinson MJ, Manoogian ENC, Zadourian A, Lo H, Fakhouri S, Shoghi A, et al. Ten-hour time-restricted eating reduces weight, blood pressure, and atherogenic lipids in patients with metabolic syndrome. Cell Metab. 2020; 31(1):92-104 e105

11. Hatori M, Vollmers C, Zarrinpar A, DiTacchio L, Bushong EA, Gill S, et al. Time-restricted feeding without reducing caloric intake prevents metabolic diseases in mice fed a high-fat diet. Cell Metab. 2012;15(6):848-60.

12. Sundaram S, Yan L. Time-restricted feeding reduces adiposity in mice fed a high-fat diet. Nutr Res (NY). 2016;36(6):603-11.

13. Cai D, Wang J, Gao B, Li J, Wu F, Zou JX, et al. RORy is a targetable master regulator of cholesterol biosynthesis in a cancer subtype. Nat Commun. 2019;10(1):4621.

14. Takeda Y, Kang HS, Freudenberg J, DeGraff LM, Jothi R, Jetten AM. Retinoic acid-related orphan receptor gamma (RORgamma): a novel participant in the diurnal regulation of hepatic gluconeogenesis and insulin sensitivity. PLoS Genet. 2014:10(5):e1004331.

15. Villanueva JE, Livelo C, Trujillo AS, Chandran S, Woodworth B, Andrade L, et al. Time-restricted feeding restores muscle function in Drosophila models of obesity and circadian-rhythm disruption. Nat Commun. 2019;10(1):2700.

16. Panda S. The arrival of circadian medicine. Nat Rev Endocrinol. 2019;15(2): $67-9$ 
17. Peirson SN, Brown LA, Pothecary CA, Benson LA, Fisk AS. Light and the laboratory mouse. J Neurosci Methods. 2018;300:26-36.

18. Meurens F, Summerfield A, Nauwynck H, Saif L, Gerdts V. The pig: a model for human infectious diseases. Trends Microbiol. 2012;20(1):50-7.

19. Walters EM, Wells KD, Bryda EC, Schommer S, Prather RS. Swine models, genomic tools and services to enhance our understanding of human health and diseases. Lab Anim. 2017;46(4):167-72.

20. Prior N, Inacio P, Huch M. Liver organoids: from basic research to therapeutic applications. Gut. 2019;68(12):2228-37.

21. Nantasanti S, de Bruin A, Rothuizen J, Penning LC, Schotanus BA. Concise review: organoids are a powerful tool for the study of liver disease and personalized treatment design in humans and animals. Stem Cells Transl Med. 2016;5(3):325-30

22. Wu LI, Chen ZY, Wang Y, Zhao JG, Xie XZ, Chen G. Organoids of liver diseases: from bench to bedside. World J Gastroenterol. 2019;25(16):1913-27.

23. Baker BM, Chen CS. Deconstructing the third dimension - how 3D culture microenvironments alter cellular cues. J Cell Sci. 2012;125(13):3015-24.

24. Broutier L, Andersson-Rolf A, Hindley CJ, Boj SF, Clevers H, Koo BK, et al. Culture and establishment of self-renewing human and mouse adult liver and pancreas 3D organoids and their genetic manipulation. Nat Protoc. 2016;11(9):1724-43.

25. Li H, Durbin R. Fast and accurate short read alignment with burrowswheeler transform. Bioinformatics. 2009;25(14):1754-60.

26. Ramos-Rodriguez RR, Cuevas-Diaz-Duran R, Falciani F, Tamez-Pena JG, Trevino V. COMPADRE: an $\mathrm{R}$ and web resource for pathway activity analysis by component decompositions. Bioinformatics. 2012;28(20):2701-2.

27. Cuchel M, Lund-Katz S, de la Llera-Moya M, Millar JS, Chang D, Fuki I, et al. Pathways by which reconstituted high-density lipoprotein mobilizes free cholesterol from whole body and from macrophages. Arterioscler Thromb Vasc Biol. 2010;30(3):526-32.

28. Chawla A, Boisvert WA, Lee CH, Laffitte BA, Barak Y, Joseph SB, et al. A PPAR gamma-LXR-ABCA1 pathway in macrophages is involved in cholesterol efflux and atherogenesis. Mol Cell. 2001;7(1):161-71.

29. Xiao S, Yosef N, Yang J, Wang Y, Zhou L, Zhu C, et al. Small-molecule RORyt antagonists inhibit T helper 17 cell transcriptional network by divergent mechanisms. Immunity. 2014;40(4):477-89.

30. Jetten AM. Recent advances in the mechanisms of action and physiological functions of the retinoid-related orphan receptors (RORs). Curr Drug Targets Inflamm Allergy. 2004;3(4):395-412.

31. Ingram DL, Dauncey MJ. Circadian rhythms in the pig. Comp Biochem Physiol A Comp Physiol. 1985;82(1):1-5.

32. Froy O. Circadian rhythms and obesity in mammals. ISRN Obes. 2012;2012: 437198.

33. Watanabe M, Houten SM, Mataki C, Christoffolete MA, Kim BW, Sato H, et al. Bile acids induce energy expenditure by promoting intracellular thyroid hormone activation. Nature. 2006;439(7075):484-9.

34. Houten SM, Schneiders MS, Wanders RJ, Waterham HR. Regulation of isoprenoid/cholesterol biosynthesis in cells from mevalonate kinasedeficient patients. J Biol Chem. 2003;278(8):5736-43.

35. Akashi M, Takumi T. The orphan nuclear receptor RORa regulates circadian transcription of the mammalian core-clock Bmal1. Nat Struct Mol Biol. 2005; 12(5):441-8.

36. Storch KF, Lipan O, Leykin I, Viswanathan N, Davis FC, Wong WH, et al. Extensive and divergent circadian gene expression in liver and heart. Nature. 2002;417(6884):78-83,

37. Brown AJ, Sun L, Feramisco JD, Brown MS, Goldstein JL. Cholesterol addition to ER membranes alters conformation of SCAP, the SREBP escort protein that regulates cholesterol metabolism. Mol Cell. 2002;10(2):237-45.

38. Brown MS, Goldstein JL. A proteolytic pathway that controls the cholesterol content of membranes, cells, and blood. Proc Natl Acad Sci U S A. 1999; 96(20):11041-8.

39. Wang $B$, Tontonoz $P$. Liver $X$ receptors in lipid signalling and membrane homeostasis. Nat Rev Endocrinol. 2018;14(8):452-63.

40. Madison BB. Srebp2: a master regulator of sterol and fatty acid synthesis. J Lipid Res. 2016;57(3):333-5.

41. Ouchi R, Togo S, Kimura M, Shinozawa T, Koido M, Koike H, et al. Modeling steatohepatitis in humans with pluripotent stem cell-derived organoids. Cell Metab. 2019;30(2):374-84 e376.

\section{Ready to submit your research? Choose BMC and benefit from:}

- fast, convenient online submission

- thorough peer review by experienced researchers in your field

- rapid publication on acceptance

- support for research data, including large and complex data types

- gold Open Access which fosters wider collaboration and increased citations

- maximum visibility for your research: over $100 \mathrm{M}$ website views per year

At $\mathrm{BMC}$, research is always in progress.

Learn more biomedcentral.com/submissions 